\title{
Altered social behavior and ultrasonic communication in the dystrophin-deficient $m d x$ mouse model of Duchenne muscular dystrophy
}

Rubén Miranda ${ }^{1,2,3^{*}}$, Flora Nagapin ${ }^{1,2}$, Bruno Bozon ${ }^{1,2}$, Serge Laroche ${ }^{1,2}$, Thierry Aubin ${ }^{1,2}$ and Cyrille Vaillend ${ }^{1,2^{*}}$

\begin{abstract}
Background: The Duchenne and Becker muscular dystrophies (DMD, BMD) show significant comorbid diagnosis for autism, and the genomic sequences encoding the proteins responsible for these diseases, the dystrophin and associated proteins, have been proposed as new candidate risk loci for autism. Dystrophin is expressed not only in muscles but also in central inhibitory synapses in the cerebellum, hippocampus, amygdala, and cerebral cortex, where it contributes to the organization of autism-associated trans-synaptic neurexin-neuroligin complexes and to the clustering of synaptic gamma-aminobutyric acid $(G A B A)_{A}$ receptors. While brain defects due to dystrophin loss are associated with deficits in cognitive and executive functions, communication skills and social behavior, only a subpopulation of DMD patients meet the criteria for autism, suggesting that mutations in the dystrophin gene may confer a vulnerability to autism. The loss of dystrophin in the $m d x$ mouse model of DMD has been associated with cognitive and emotional alterations, but social behavior and communication abilities have never been studied in this model.
\end{abstract}

Methods: Here, we carried out the first in-depth analysis of social behavior and ultrasonic communication in dystrophin-deficient $m d x$ mice, using a range of socially relevant paradigms involving various degrees of executive and cognitive demands, from simple presentation of sexual olfactory stimuli to social choice situations and direct encounters with female and male mice of various genotypes.

Results: We identified context-specific alterations in social behavior and ultrasonic vocal communication in mdx mice during direct encounters in novel environments. Social behavior disturbances depended on intruders' genotype and behavior, suggesting alterations in executive functions and adaptive behaviors, and were associated with selective alterations of the development, rate, acoustic properties, and use of the ultrasonic vocal repertoire.

Conclusions: This first evidence that a mutation impeding expression of brain dystrophin affects social behavior and communication sheds new light on critical cognitive, emotional, and conative factors contributing to the development of autistic-like traits in this disease model.

Keywords: Dystrophin, Dystrophinopathies, Dystroglycan, Autism, Executive functions, Ultrasonic vocalizations, Social behavior, Neuroligin, Mdx mice

\footnotetext{
*Correspondence: ruben.miranda@pdi.ucm.es; cyrille.vaillend@u-psud.fr

${ }^{1}$ CNRS, Neuroscience Paris Saclay Institute, UMR 9197, Orsay 91405, France

Full list of author information is available at the end of the article
} 


\section{Background}

Studies of genetic factors underlying the comorbid diagnosis of autism in genetic syndromes associated with intellectual disability, such as in the Duchenne muscular dystrophy (DMD) and milder Becker condition (BMD), may open new routes to understand the common biological mechanisms and intricate combination of multiple genes and mutations involved in the complex etiology of autism [1]. DMD and BMD are recessive Xlinked neuromuscular diseases mainly affecting males and caused by mutations in the dmd gene that encodes the 427-kDa cytoskeleton-associated dystrophin protein (Dp427) [2]. Both syndromes are associated with nonprogressive cognitive deficits, leading to intellectual disability in about $30 \%$ of the patients [3]. The prevalence rate of autism spectrum disorders (ASD) is significantly increased (3 to $>10 \%$ ) in DMD/BMD compared to the general population (<1.5\%) (http://www.cdc.gov/) [4-7]. This may be attributed to the loss of dystrophin within a functional network of brain structures including the cerebellum, hippocampus, amygdala and associative cortical areas $[2,8]$, which is reminiscent of the integrated circuit proposed as the neural substrate of ASD [1,9]. Social behavior problems and poor facial affect recognition have been described in DMD children [10, 11], as well as reading and language retardation and oral phonological deficiency [12], showing that brain dystrophin loss alters both social behavior and communication.

The phenotypic heterogeneity in dystrophinopathies likely relies on individual differences in genetic background and on the variety of mutation profiles within the $d m d$ gene, which may lead to the sole loss of brain full-length dystrophin (Dp427) or to a cumulative loss of shorter dystrophins encoded by distinct internal promoters, such as Dp140 and Dp71 [13]. While the presence of mental retardation in one third of DMD patients is closely related to distal mutations affecting expression of C-terminal forms of dystrophin (e.g., [13]), no clear genotype-phenotype relationship was reported for the comorbid diagnosis of ASD, and patients with altered social behavior and communicative skills do not necessarily display mental retardation $[6,10,11,14]$. However, one patient with DMD and autism was shown to carry a submicroscopic deletion encompassing exons 12-25 of the dystrophin transcript, suggesting that the loss of Dp427 is sufficient to induce vulnerability to autism [15]. The dystrophin-associated complex links the actinbased cytoskeleton to the extracellular matrix in both the muscle and brain, where it interacts with specific membrane receptors and ion channels [16]. Brain alterations associated with Dp427 loss are mainly located at the synaptic level and involve impaired gammaaminobutyric acid (GABA)ergic function and excitation/ inhibition balance; key mechanisms also implicated in ASD [17]. Dystroglycan, a central component of dystrophin complexes interacts with the autism-associated trans-synaptic neurexin-neuroligin complex [18-20], suggesting a putative mechanism underlying alterations in social behavior and/or communication in DMD. In the present study, we have characterized alterations in social behavior and ultrasonic communication in the $m d x$ mouse model of DMD, which presents a nonsense point mutation (C-to- $\mathrm{T}$ transition) in exon 23 of the $d m d$ gene that aborts full-length dystrophin (Dp427) expression [21]. We used a combination of behavioral and bioacoustics measures previously validated as relevant approaches to characterize autistic traits in mice. Parameters have been quantified in a range of socially relevant paradigms involving various degrees of executive/cognitive demand, from simple presentation of sexual olfactory stimuli to social choice situations and direct encounters with female and male mice of various genotypes, which enabled the identification of critical cognitive, emotional, and conative factors contributing to the phenotype.

\section{Methods}

\section{Animals}

C57BL/10ScSn-Dmd ${ }^{m d x} / \mathrm{J}$ mutant males $(m d x)$ and littermate wild-type (WT) controls were bred in our laboratory [22]. Male siblings were kept in groups (three to six mice) under a 12-h light-dark cycle (light on 7:00 a.m.) with food and water ad libitum. A first cohort of 5 -month-old male mice $(m d x=13$; WT $=10)$ was placed in individual cages for 1 week and then successively tested for social interaction with females, response to females' urine and cage bedding, social interaction with males, investigation of anesthetized females, and social choices in the three-chamber test, with at least 48-h intervals between tests (total duration of isolation period 4-5 weeks). A second cohort of 3-month-old male mice ( $n=15$ per genotype) was placed in individual caging for 2 months to increase the level of territorial aggressiveness before being tested in the resident-intruder agonistic paradigm. In both experiments, mice were 5 months old at the start of testing. Adult control mice ( $>3$ months) used for encounters or for bedding/ urine collection were obtained from Harlan Laboratories (C57BL/10ScSn01aHsd) and Janvier Europe (C3H and $\mathrm{balb} / \mathrm{c}$, all males) and were reared in groups throughout. Mice pups aged 3 to 9 postnatal days (PNDs) from four different litters $(m d x=7$; WT $=15)$ were tested for neonatal ultrasonic vocalizations (USVs). Experiments were conducted blind to genotype and in accordance with the European Communities Council Directive of 24 November 1986 (CEE 86/609/EEC), EU Directive 2010/63/EU and French National Committee (87/848), and following 
guidelines of the local animal facility (Direction Départementale de la Protection des Populations, DDPPV-France, agreement \# B91-471-104).

\section{Recording of ultrasonic vocalizations}

Mouse ultrasonic calls were recorded in mouse pups following mother separation and in adult mice during interaction tests and exposure to olfactory stimuli as in previous studies [23-27]. For recordings of USVs in neonates, mdx and WT breeding pairs were housed in standard Plexiglas cages $(20 \times 30 \mathrm{~cm})$. The day of birth was considered PND0 and pups were tested every day from PND3 to PND9. At the time of testing, each pup was separated from its mother and placed into an empty cage $(20 \times 30 \mathrm{~cm})$ inside a sound-attenuating Styrofoam box to assess USVs for $5 \mathrm{~min}$. Room temperature was kept at $22 \pm 1{ }^{\circ} \mathrm{C}$. Pups were placed back into their home cage after testing. Individuals were tagged by toe clipping to allow identification during successive days. Data from all individual pups were pooled within each genotype, as no obvious sex-specific call patterns were observed. For adult mice, USVs were recorded in a range of experimental conditions as described below in the "Behavioral testing" section, except in the resident-intruder test performed in residents' home cage, due to the noise associated with the pursuits and agonistic behaviors, and in the social approach in the threechambered test, due to the size and architectural constraints of the apparatus.

USVs were recorded with a condenser ultrasound microphone (Avisoft Bioacoustics, Germany; CMPA$\mathrm{P} 48 / \mathrm{CM} 16$, frequency response $\pm 3 \mathrm{~dB}$ within the range $10-180 \mathrm{kHz}$ ) suspended $15 \mathrm{~cm}$ above the cage and connected to a TASCAM HD-P2 digital recorder. Vocalizations were sampled at $192 \mathrm{kHz}$ with a 16-bit dynamic. Recordings were analyzed with the Avisoft SASLab Pro (v4.40) signal processing software. Spectrograms were thus generated (fast Fourier transform (FFT)-length of 1024 points, overlap of $75 \%, 100 \%$ Frame, Hamming window) to follow the frequency modulation. A highpass FFT filter (cutoff frequency of $25 \mathrm{kHz}$ ) was applied to reduce the background noise. A call, or syllable, was defined as a unit of sound separated by silence from other sound units that may consist of one or more "notes" or continuous markings on a sonogram [23]. A sequence, or bout, was defined as a succession of at least two calls separated by silent intervals less than $200 \mathrm{~ms}$. Number and mean duration of calls and sequences were quantified, and the total time spent calling was computed by summing durations of each call. The call peak frequency (Pfreq) was defined as the frequency of maximum amplitude in the spectrum, while the call peak amplitude (Pamp) corresponded to the amplitude at peak frequencies at the start and end points of each call. Measures taken in repeated trials were averaged for statistical comparisons.

\section{Semi-automatic quantification of USV subtypes}

A qualitative detection of ultrasonic calls was performed in both pups $(N=21,060$ calls $)$ and adults $(N=79,601$ calls) using a combination of custom visual basic for application (VBA)-based macros and visual inspection of sonograms (Additional file 1: Supplementary method section), which enabled identification of 10 waveform pattern categories [24, 25, 27] (see Fig. 1): upward: continuous frequency increase of at least $1.5 \mathrm{~Hz}$ per $10-\mathrm{ms}$ bins, with eventually flat steps; downward: continuous frequency decrease of at least $1.5 \mathrm{~Hz}$ per $10-\mathrm{ms}$ bins, with eventually flat steps; peak: frequency-modulated call showing continuous increase in frequency followed by a continuous decrease; $u$-shape: frequency-modulated call showing continuous decrease in frequency followed by a continuous increase; flat: constant frequency with no modulation $>1.5 \mathrm{~Hz}$ per 10-ms bins; short: duration $<10 \mathrm{~ms}$; sinusoidal (complex): two or more directional changes in frequency in distinct directions; frequency jump (composite): two or more components displaying discontinuous frequency "jump (s)" on the sonographic

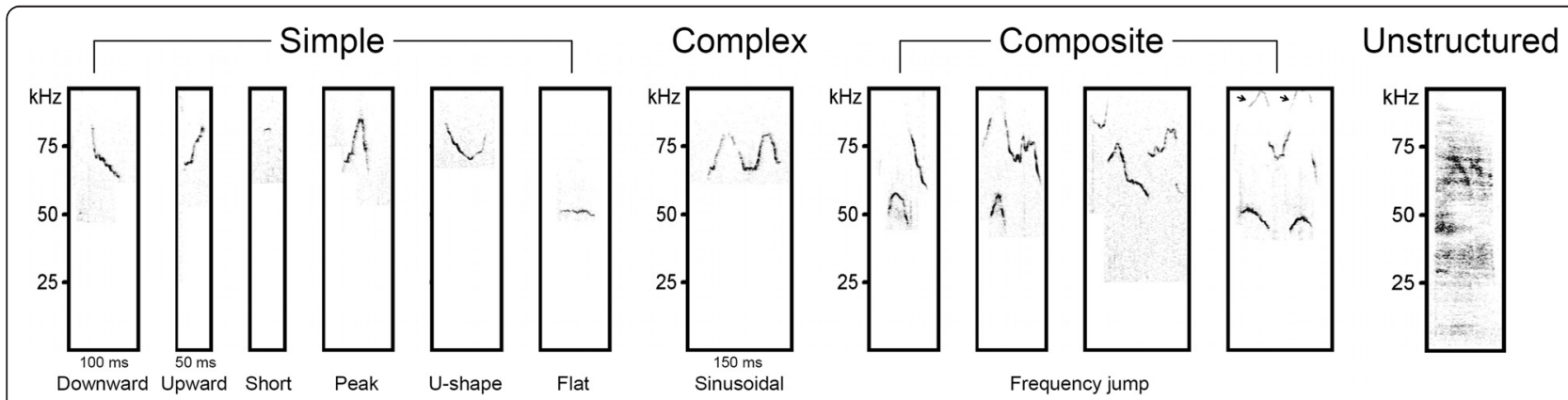

Fig. 1 Classification of mouse ultrasonic calls. Sample images illustrate the main categories identified in mouse ultrasonic calls. Arrows in the last example of frequency jump USV indicate the presence of harmonic components, which have been used as an additional classification criterion. The broader (inclusive) categories grouping several call subtypes are indicated on top (i.e., simple, complex, and composite categories) 
representation but without gap on the time scale; harmonic: fundamental frequency slightly modulated combined with an amplified harmonic component. Because harmonics were observed in different call categories, each call was first assigned to one of the above categories and then further labeled as "harmonic" or "non-harmonic"; unstructured: without main sound component and frequency shape that could be assimilated to any of the other categories. Calls were then grouped in a reduced number of broader (inclusive) categories defined as: simple (i.e., upward, downward, flat, short, peak, and $\mathrm{u}$-shaped), complex (i.e., sinusoidal), and composite (i.e., frequency jump).

To detect and classify calls, an automatic thresholdbased detection of calls was first performed by extracting time/frequency data every $10 \mathrm{~ms}$ for each call (Avisoft SASLab Pro v4.40). Data were then imported into Excel software (Microsoft corp.) and a custom VBA macro was run for automatic classification of calls: Within each call, each 10-ms interval was assigned to a qualitative value representing ascending, descending, or flat changes in frequency $(\geq 1.5 \mathrm{~Hz})$. For the total duration of a call, the macro then integrated these 10-ms sequences of qualitative information to determine the category to which the call belongs (upward, downward, flat, peak, ushaped, or sinusoidal). Short calls were simply identified based on their duration. Automatic threshold detection was not accurate to identify unstructured, harmonic, and frequency jump (i.e., composite) calls (Fig. 1), or in conditions of low signal to noise ratio. In such conditions, an accurate classification was achieved manually and calls were assigned to adequate categories using the interactively (section labels) function of Avisoft software. Data derived from manual inspection of sonograms were transferred into Excel software and combined with previous automatically classified data, using a second VBAbased custom macro. Using the start points of each call as a reference, this second macro overwrote and corrected previous automatic classification data with manually defined categories when appropriate. A detailed description of the classification strategy is provided in the Additional file 1 (supplementary method section), and VBA-based macros are available upon request to corresponding authors.

\section{Behavioral testing}

\section{Male-female social interaction}

Adult male mice of each genotype were confronted with control (WT) females for 3 min during four consecutive days, to ensure that all subjects reliably emitted USVs. Each test male was confronted with a different female in every trial. For each testing day, test males were first familiarized to the test cage (transparent Plexiglas box, $20 \times 30 \times 14 \mathrm{~cm}$, with floor filled with fresh bedding) for
30 min, an unknown control female was introduced, and social interaction was recorded for $3 \mathrm{~min}$. Female estrous stage was verified each day after behavioral testing by vaginal smear cytology. Behavioral responses were analyzed during the first session. Behavioral responses were videorecorded, and the sniffing or snout contacts elicited by the resident males were quantified manually using event-recorder keys in ANY-maze software (Stoelting, USA). The latency of first contact, mounting attempts, frequency, and duration of contacts were analyzed. Contacts were classified as orofacial (directed towards the head/neck/mouth area), orogenital (towards the anogenital area), or directed towards other body parts (flank area).

\section{Male exposure to female urine}

Test mice were first acclimatized to the testing room and cage for $30 \mathrm{~min}$ and then tested during two consecutive days. Each daily session consisted in three consecutive trials (5-min duration) with a 5-min inter-trial interval, consisting in the successive presentation of female mouse urine (trial 1), distilled water (trial 2), and mouse urine from a different female (trial 3). A 20- $\mu$ l drop of urine or distilled water on a cotton swab was placed in the testing arena hanging from a telescopic clamp close to the microphone (about $15 \mathrm{~cm}$ above the floor). Fresh urine was previously collected from WT female donors by holding them by the scruff onto a metal grid, above a clean aluminum foil. In case handling was not sufficient to stimulate urination, the mouse ventral area was gently stroked in the anteroposterior direction [28]. The urine on the foil was immediately pipetted into Eppendorf tubes for storage at $-80{ }^{\circ} \mathrm{C}$ and classified according to individual estrous stage (determined by vaginal smear cytology after urine collection). On the day of testing, frozen urine from proestrous-estrous females (matching peak levels of estradiol and progesterone) was thawed at room temperature and pipetted onto clean cotton swabs. Mice were videotracked (ANY-maze, Stoelting, USA) to analyze the distance travelled and the frequency and duration of mobile episodes. Sniffing of the cotton swab was manually quantified using eventrecorder keys in ANY-maze and the percentage time sniffing compared between genotypes.

\section{Male exposure to female cage bedding}

The test mice were first acclimatized to the testing room and cage for $30 \mathrm{~min}$. Then, a daily session consisted in two consecutive 3-min trials. During the first trial, bedding from a females' cage (approximately $25 \mathrm{ml}$, cage unchanged for 1 week) was presented in one of two identical recipients $(4 \times 4 \times 1 \mathrm{~cm})$ placed at opposite corners of the testing cage. In trial 2, the previously empty recipient was filled with new bedding collected from a 
different females' cage. Location of olfactory stimuli used in trials 1 and 2 was balanced across animals. The distance travelled and the frequency and duration of mobile episodes were quantified. The frequency and duration (expressed as percentage time) of bedding recipients sniffing were manually scored using event-recorder keys in ANY-maze (Stoelting, USA).

\section{Male exposure to anesthetized female}

Following acclimatization to the test cage as above, the test mice were confronted to an anesthetized control female (anesthesia: IP injections of $100 \mathrm{mg} / \mathrm{kg}$ ketamin and $12 \mathrm{mg} / \mathrm{kg}$ xylazin) during two 3-min successive trials performed on the same day with an inter-trial interval of $2 \mathrm{~min}$. A different female was introduced in the test cage in each trial. The frequency and duration (percentage time) of contacts performed by the test mice were manually quantified using event-recorder keys in ANYmaze (Stoelting, USA).

\section{Male-male reciprocal social interaction}

Social interaction was assessed as for the male-female interaction test above. Resident male mice were confronted to unknown male intruders (either of a WT or $m d x$ genotype) for $3 \mathrm{~min}$ on two consecutive days. Behavioral responses were manually scored in both resident and intruder mice including the latency of the first contact, number of dominance responses (resident putting paws onto intruders back), frequency and duration (percentage time) of pursuits, orofacial sniffing, orogenital sniffing, and body sniffing. No mounting, fighting, and wrestling behaviors were observed.

\section{Social approach behavior in a three-chamber test}

Apparatus and paradigm have been previously described [29]. The apparatus was a rectangular three-chambered box fabricated from clear polycarbonate. Dividing walls with manual retractable doorways (width $10 \mathrm{~cm}$; height $20 \mathrm{~cm}$ ) enabled access into each chamber $(20 \times 40 \times 22 \mathrm{~cm})$. The box was cleaned with alcohol, and fresh bedding was added between trials. The middle chamber was used to confine test mice at the beginning of test trials, while each of the two side chambers contained an empty transparent polycarbonate tube $(8 \mathrm{~cm}$ in diameter) in which social (stranger mouse) and nonsocial (object) stimuli could be confined. These confinement tubes were drilled with holes $(1-\mathrm{cm}$ diameter; $2-\mathrm{cm}$ spaced) to allow limited contact with the confined stimulus. Control male mice used as social stimuli (strangers) were familiarized to the confinement tubes during 4 days (30 min per day) before the start of the experiment. Then, testing consisted of three trials: For trial 1 (habituation), the test mouse was placed in the middle chamber for $2 \mathrm{~min}$, the doorways were then opened, and the mice could freely explore the test box for $10 \mathrm{~min}$ after which they were confined in the middle chamber for $30 \mathrm{~s}$ before proceeding with the next trial. During trial 2 (sociability), an unknown mouse (stranger 1) was introduced in one of the confinement tubes in one side chamber, whereas an object made of Lego ${ }^{\circ}$ pieces was enclosed in the other tube in the opposite side chamber. Location of stranger 1 in the left or right side chamber was balanced across subjects. Upon door re-opening, the test mouse was allowed to explore the test box and tubes for $10 \mathrm{~min}$ and was then confined again in the middle chamber before the next trial. During trial 3 (preference for social novelty), the object present in trial 2 was replaced by a novel unfamiliar mouse (stranger 2), and the test mouse was then given the possibility to interact with both stranger 1 and stranger 2 for $10 \mathrm{~min}$. Behavior was videotracked during all trials (ANYmaze software) to analyze general activity (distance travelled, rearing and leanings, self-grooming, periods of activity and inactivity). Social behavior was reflected by the percentage time spent and number of entries in the side chambers containing the confined stimuli, as well as by the frequency and duration (percentage time) of sniffing episodes directed against the confinement tubes.

\section{Resident-intruder test}

The protocol was adapted from previously described methods [30]. Test mice of both genotypes $(m d x$ and WT littermates) were initially changed to individual caging $(20 \times 30 \mathrm{~cm}$ cages $)$ for 2 months without bedding change. Three distinct strains of mice were used as intruders, based on their known differences in social behavior: male C57BL/10 mice aged 3-4 months, which were of the same genetic background as the resident test mice; males of the $\mathrm{C} 3 \mathrm{H}$ strain, known as non-aggressive mice; and males of the balb/c strain known for their high intraspecific aggressiveness [31]. Each test mouse was successively confronted to these three types of intruders within a 2-week period (5-day intervals between trials).

Behavior was videorecorded for 6 min after placing the intruder in the resident's home cage. The following behavioral parameters were coded manually using eventrecorder keys (ANY-maze software): contacts initiated by the resident, contacts initiated by the intruder, fights, pursuits, rearings, dominant behavior (putting a paw on the body of the other mouse and/or mounting), as well as periods of immobility either during or between social contacts. The specific nature of the contacts was further specified as orofacial, orogenital, and body sniffing.

\section{Statistical analyses}

Data presented as means \pm SEM correspond to averages of responses expressed in successive trials, as no significant variations in performance were detected across repetitive trials in a preliminary analysis using repeated 
measures analysis of variance (ANOVA). Ultrasonic calls and behaviors were analyzed using two-way ANOVAs with one between-subject factor (genotype: WT or $m d x$ ) and one dependent variable or within-subject factor when appropriate (postnatal day, task, type of contact, chamber), followed by Tukey post hoc tests. Correlations were calculated using the Pearson correlation coefficient. $P$ values $<0.05$ were considered statistically significant. The two-tailed Kolmogorov-Smirnov (KS) test was used to analyze the distribution of call duration (significance threshold: $p<0.005)$.

\section{Results}

\section{Social approach behavior in the three-chambered box}

Spontaneous activity was significantly lower in $m d x$ than in WT mice during habituation (Table 1; trial 1; $p<0.05)$. Both genotypes explored the side chambers more than the central zone (percentage time in chamber, $p<0.05)$, with no place preference for any side chamber (Fig. 2a). Sociability (trial 2) was comparable between genotypes with a clear preference for the chamber containing the social stimulus (chamber effect: $p<0.05$; genotype effect and genotype $\times$ chamber interaction: $p>0.05$; Fig. 2b). In trial 3 (preference for social novelty; Fig. 2c), mice spent more time sniffing the novel mouse than the familiar mouse (percentage time sniffing, $p<0.05$ ) and no significant genotype effect was detected, demonstrating normal preference for social novelty and short-term social memory in $m d x$ mice.

\section{Reciprocal social interactions}

\section{Social interaction in a novel environment}

The social behavior of $m d x$ resident males differed depending on the sex and genotype of the intruder. As shown in Fig. 3a, $m d x$ mice initiated fewer contacts with females as compared to WT mice $(p<0.005$; Fig. 3a), which was not associated with changes in specific types of contacts. In male-male encounters (Fig. 3b-d), the

Table 1 Behavioral activity during habituation in the threechambered box. The distance run and time spent mobile/active were significantly lower in $m d x$ than in wild-type (WT) mice. However, rearings and self-grooming activity $(p>0.05)$ were unaffected

\begin{tabular}{lrrl}
\hline & WT $(n=10)$ & $m d x(n=13)$ & $P$ values \\
\hline Distance run $(m)^{*}$ & $47.93 \pm 2.36$ & $40.32 \pm 1.37$ & 0.008 \\
Time mobile $(s)^{*}$ & $556.84 \pm 7.23$ & $536.38 \pm 6.26$ & 0.044 \\
Time active $(\mathrm{s})^{*}$ & $564.27 \pm 6.81$ & $543.35 \pm 5.62$ & 0.026 \\
Rearings $(n)$ & $83.70 \pm 8.65$ & $95.15 \pm 6.43$ & 0.289 \\
Self-grooming $(n)$ & $2.20 \pm 0.61$ & $2.08 \pm 0.38$ & 0.860 \\
Grooming duration $(\mathrm{s})$ & $8.44 \pm 2.31$ & $6.86 \pm 1.09$ & 0.512 \\
\hline
\end{tabular}

${ }^{*} p<0.05$ $m d x$ resident mice also displayed fewer contacts towards $m d x$ male intruders $(p<0.05)$ but conversely initiated more contacts than control residents when confronted to WT intruders $(p<0.05)$ (Fig. 3b). In any cases, no fights were observed and the latency of the first contact (all $<10 \mathrm{~s}$ ) and the number of dominant acts initiated by resident test mice (Fig. 3c) were comparable regardless of the intruder's genotype $(p>0.05)$. However, the increased number of contacts with WT intruders, as shown in Fig. 3b, was associated with the initiation of an increased number of pursuits directed against the WT intruders $(p<0.05)$. This was not observed when $m d x$ residents were confronted with $m d x$ intruders $(p>0.05$; Fig. 3d), showing that pursuit behavior, as well as the number of contacts, varied depending on the intruder's genotype.

Interestingly, the intruder's behavior also varied depending on the resident's genotype (Fig. $3 \mathrm{e}-\mathrm{g}$ ). The behavior of $m d x$ intruders was not influenced by the resident's genotype while, in contrast, the behavior of WT intruders varied when confronted with $m d x$ residents: indeed, the WT intruders initiated more contacts (Fig. 3e), dominant acts (Fig. 3f), and pursuits (Fig. 3g) during interactions with $m d x$ residents than with other WT residents (all parameters, $p<0.05$ ). This suggests that $m d x$ mice, when acting as passive (or receptive) residents, were showing more submissive responses compared to controls.

\section{Resident-intruder agonistic interactions}

To determine whether changes in intruder's aggressiveness influenced the variable behavior of $m d x$ resident mice in the experiments above, a different group of male residents was submitted to a longer period of social isolation (2 months before testing) and forced encounters with intruders of three distinct genotypes were performed in the resident's home cage (instead of a novel cage) to increase agonistic interactions. Fights were scarce with $\mathrm{C} 57 \mathrm{BL} / 10$ and $\mathrm{C} 3 \mathrm{H}$ intruders but more consistently observed with balb/c intruders (Fig. 4a). Although pursuits and fights were mainly initiated by residents, the intensity of aggressiveness was thus dependent on the intruders' behavior. Still, the incidence of fights was relatively low, which allowed reliable recording of social behaviors. Self-grooming episodes were scarce and very short $(<4 \mathrm{~s}$; no significant genotype effect). In this experiment, the intruders' genotype also influenced the quantity of social interactions initiated by residents, as revealed by significant intruder's genotype $\times$ dependent variable interactions (contact latency: $p<0.05$; number: $p<0.01$; duration: $p<0.001$ ). Figure $4 \mathrm{~b}$ shows the longer duration of contacts in residents of both genotypes in presence of lowaggressiveness $\mathrm{C} 3 \mathrm{H}$ intruders $(p<0.001)$. 


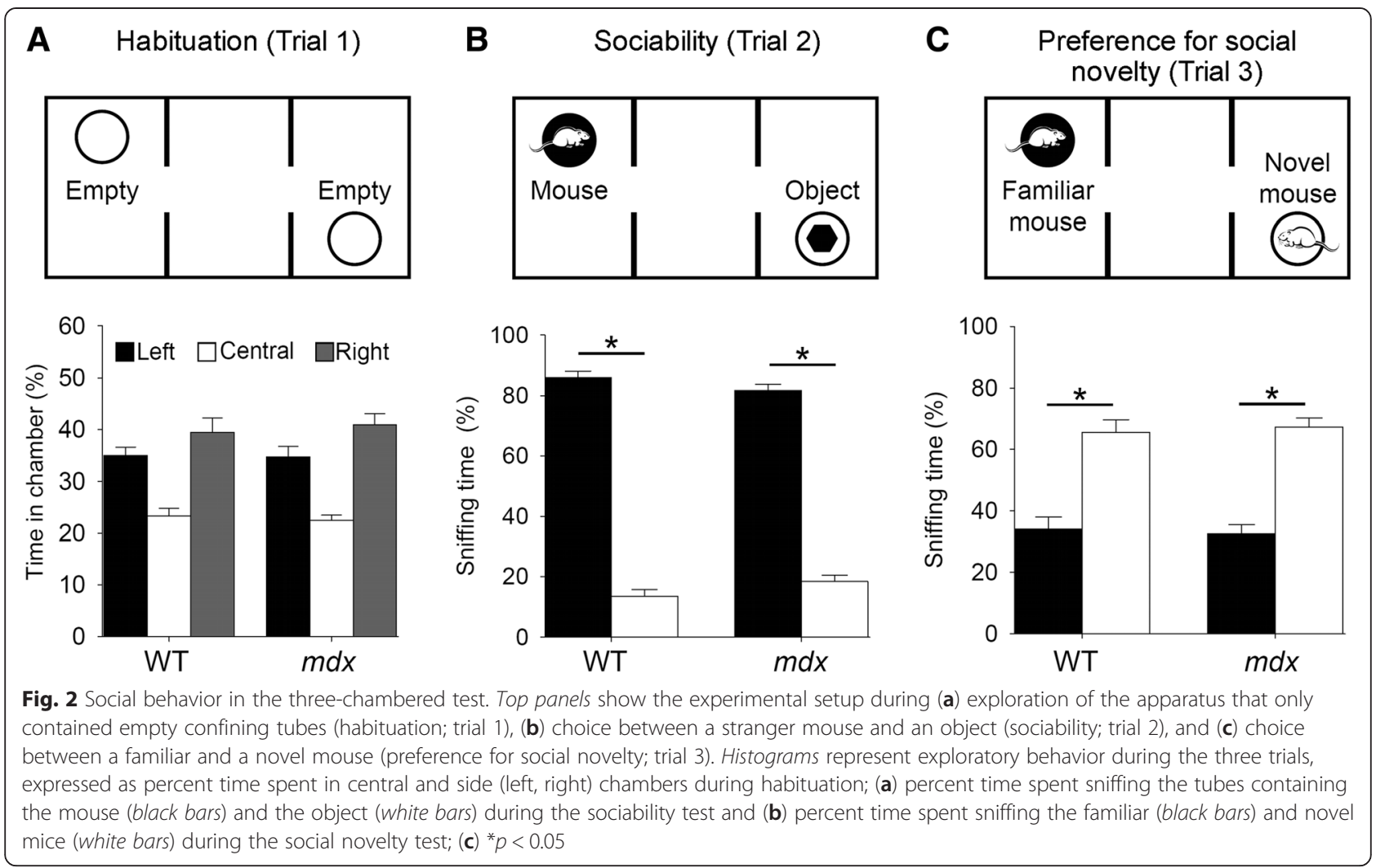

Conversely, intruder mice displayed shorter latencies to interact with $m d x$ as compared to WT residents (genotype: $p<0.05$; genotype $\times$ intruder interaction: $p=0.3$; Fig. $4 c$ ) associated with a slightly longer duration of contacts $(p=0.09$; Fig. $4 \mathrm{~d})$. To better understand why the intruders behaved differently when confronted with $m d x$ residents, we compared the quality of the social interactions when intruders were of the $\mathrm{C} 3 \mathrm{H}$ and balb/c genetic backgrounds during the first $3 \mathrm{~min}$ of testing (Table 2). There was an increased expression of a specific set of behavioral responses, such as orofacial contacts, pursuits, dominant acts, and freezing behavior, when resident mice were confronted with $\mathrm{C} 3 \mathrm{H}$ intruders as compared with interactions involving balb/c intruders. Moreover, the nonaggressive $\mathrm{C} 3 \mathrm{H}$ intruders displayed more dominant acts towards $m d x$ mice, while the more aggressive balb/c mice directed dominant acts preferentially towards WT residents (Fig. 4e). Periods of immobility (freezing), which likely reflected fear responses, were more frequent and longer during physical contacts in $m d x$ residents compared to WT, while the quantity of rearings was conversely decreased (Table 2). Interestingly, immobility was comparable between genotypes during periods with no physical contacts, suggesting that the enhanced freezing in $m d x$ mice was selectively triggered by social contact. Enhanced fear/defensive responses in $m d x$ mice likely have favored intruder's dominant behavior, as freezing was more prominent when $m d x$ mice interacted with the $\mathrm{C} 3 \mathrm{H}$ intruders (Fig. 4f), which also showed the largest amount of dominant behaviors towards $m d x$ mice (Fig. $4 \mathrm{e}$ ).

\section{Exposure to olfactory sexual stimuli}

Female olfactory stimuli and the presence of irresponsive (anesthetized) females elicited comparable behavioral approaches in $m d x$ and WT mice. Both genotypes spent more time sniffing anesthetized females than female cage bedding and urine (task effect: $p<0.001$; genotype and interaction effects: $p>0.05$; Additional file 2: Figure S1).

\section{Ultrasonic vocalizations in pups}

Both genotypes showed a similar developmental curve for the number of isolation-induced USVs (Fig. 5a). The number of calls, sequences, calls per sequence, as well as the call amplitude and duration and time spent vocalizing were comparable between genotypes (all parameters; $p>0.05$ ). However, call peak frequencies were higher in $m d x$ than WT mice at PND3 $(p<0.05$; Fig. 5b, c), suggesting an early but transient alteration in USV properties in neonate $m d x$ mice.

Most isolation calls were classified (Fig. 1) in the simple-type category, while composite and complex types were less represented. At PND4, $m d x$ pups produced fewer simple $(p<0.05$; Fig. $5 \mathrm{~d})$ and more composite calls compared to WT pups $(p<0.05$; Fig. 5 h), while 


\section{Resident's behavior}
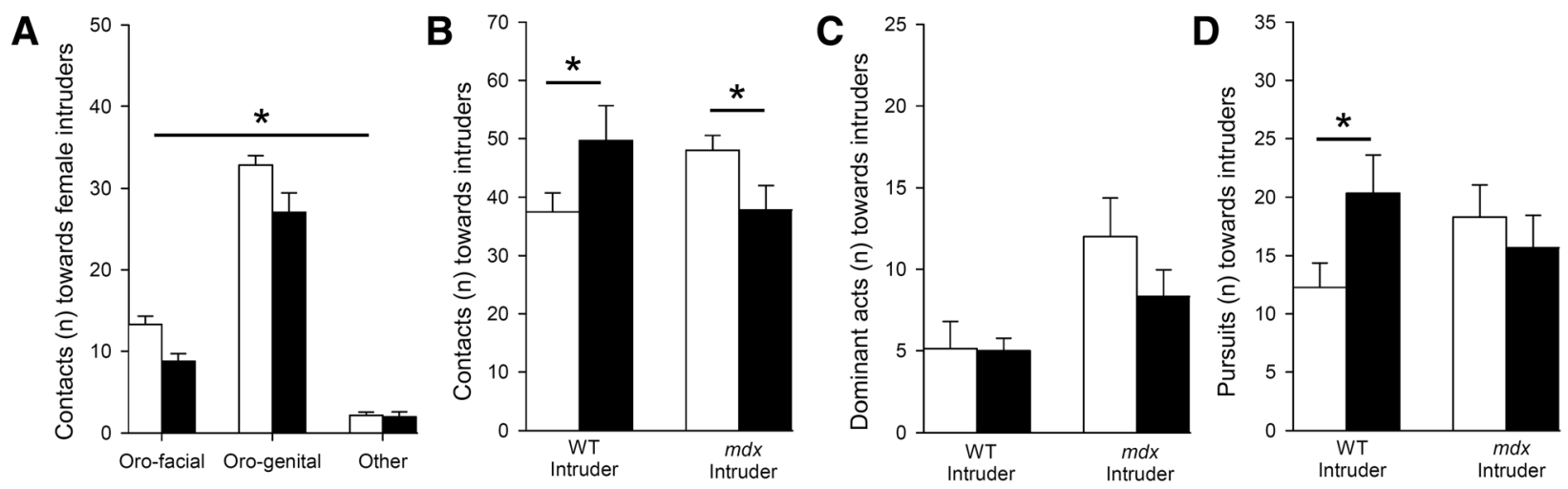

\section{Intruder's behavior (Male-male interactions)}

WT male residents

$m d x$ male residents
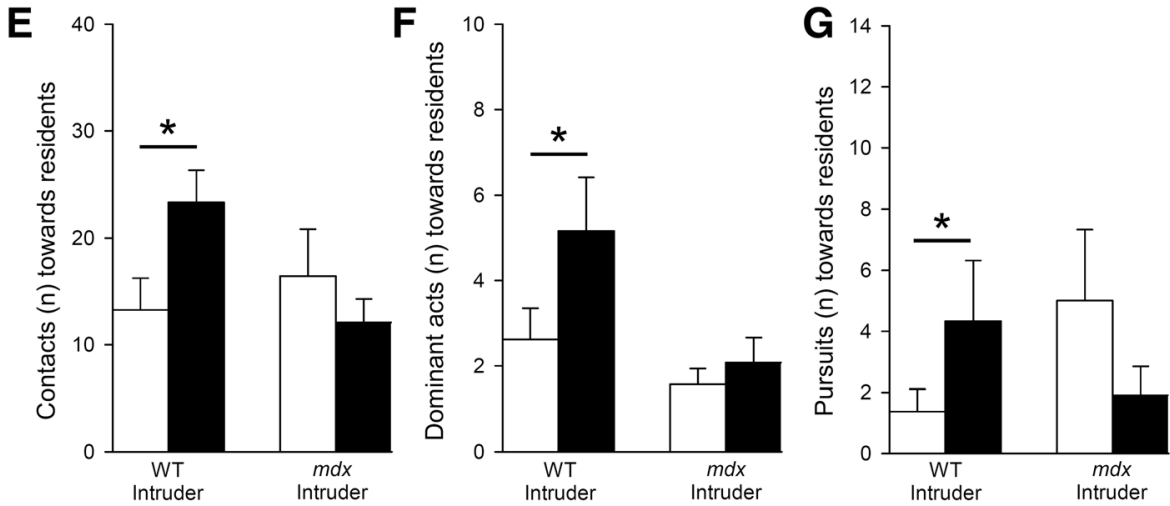

Fig. 3 Reciprocal social interactions in a novel cage. a Male-female interactions expressed by the number of orofacial, orogenital, and body contacts initiated by WT and $m d x$ resident mice towards control intruder females. b-d Male-male interactions expressed by the behavioral responses initiated by WT (white bars) and $m d x$ resident male mice (black bars) during interactions with WT and mdx male intruders (intruder's genotype indicated on the $X$-axis). Histograms show the number of contacts (b), dominant acts (c), and pursuits (d) performed by resident test mice. e- $\mathbf{g}$ Behaviors initiated by WT and $m d x$ intruder male mice during interactions with WT and $m d x$ male residents. Histograms show the number of contacts $(\mathbf{e})$, dominant acts $(\mathbf{f})$, and pursuits $(\mathbf{g})$ performed by the intruders. ${ }^{*} p<0.05$

they produced fewer downward calls at PND3 $(p<0.05$; Fig. 5e) and fewer peak calls during PND6 and PND7 ( $p$ $<0.05$; Fig. 5f). Overall, $m d x$ mice tended to produce fewer simple and sinusoidal calls (Fig. $5 \mathrm{~d}$, g) but more composite calls (Fig. 5h), suggesting transient alterations in the use of ultrasonic vocal repertoire during postnatal development.

\section{Ultrasonic vocalizations in adults}

In adult WT mice, the largest amounts of USV was detected during interactions with freely moving females, then in the presence of anesthetized females, then with other male encounters, and finally in response to olfactory stimuli (female cage bedding and urine) (see Fig. $6 a-d)$. This confirms that syllable production in mice is modulated by the social context. The latency of the first call was comparable between genotypes in all conditions $(p>0.05)$. However, the call rate (Fig. 6a), percent time vocalizing (Fig. 6b), and call duration (Fig. 6c) varied depending on the experimental context and genotype (task effect: $p<0.001$, genotype $\times$ task interaction: $p<0.01)$. The rate and duration of calls were particularly reduced in $m d x$ compared to WT mice during interactions with $m d x$ male intruders (MM- $m d x$ in Fig. $6 \mathrm{a}-\mathrm{c} ; p<0.05)$ and in the presence of anesthetized females (Fig. 6a-c; $p<0.05$ ). There was a task-dependent 


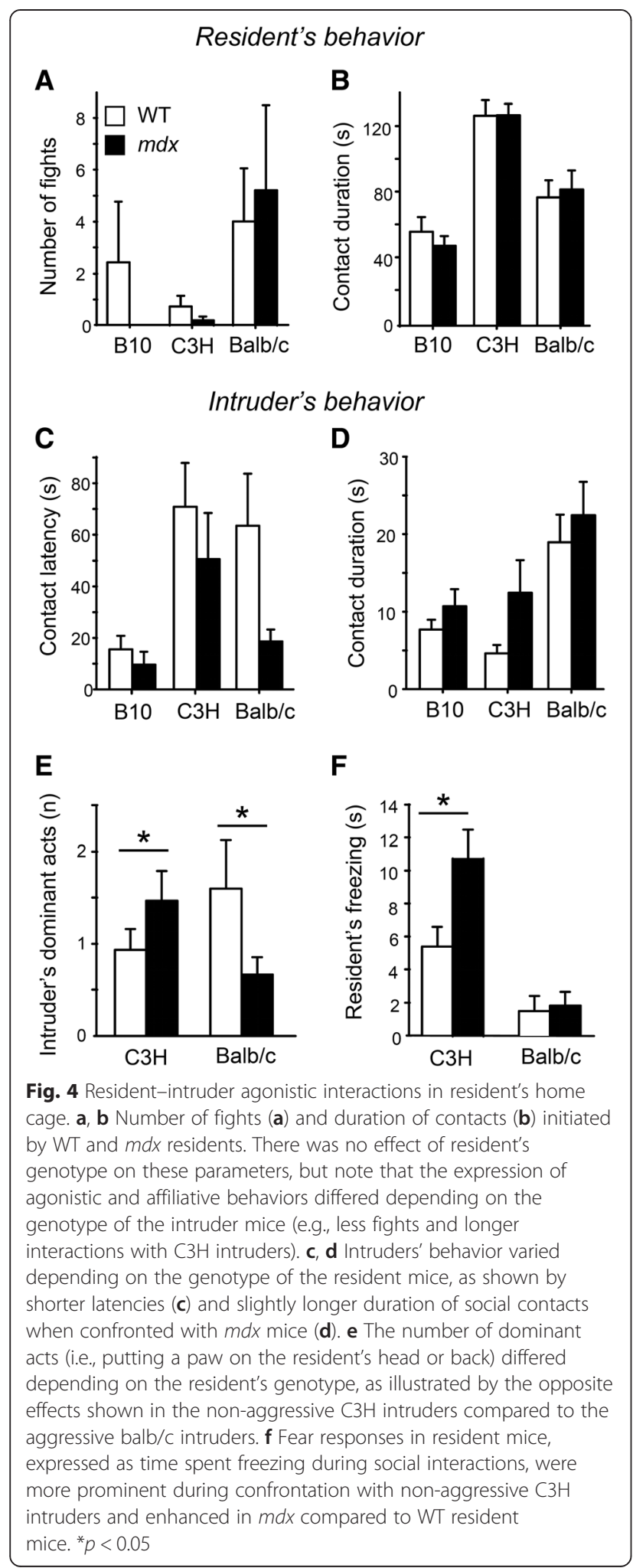

reduction in the number of sequences in $m d x$ mice (task effect: $p<0.001$; genotype $\times$ task interaction: $p<0.005$; Fig. 6d), which was particularly reduced during interaction with anesthetized females $(p<0.05)$. Duration of sequences was unaffected (Fig. 6e). In all tests except during urine presentation, $m d x$ mice sequences contained fewer syllables (sequence elements; Fig. 6f) (genotype effect: $p<0.05$; genotype $\times$ task interaction: $p>0.05$ ), which was likely linked to the reduced call rate in this genotype. Call peak frequencies were globally unaffected (Fig. $6 \mathrm{~g}$, h). However, the peak amplitudes were less intense in $m d x$ compared to WT mice during exposure to anesthetized females and female bedding and during interactions with $m d x$ male intruders $(p<0.005$; Fig. $6 \mathrm{i}, \mathrm{j})$. Analysis of the correlations between behavioral and acoustic parameters (Additional file 3: Supplementary results section) revealed that the significant correlations detected in WT mice were absent in $m d x$ mice, suggesting a disorganization of the relationships between social behavior and ultrasonic communication in this model.

Because the large repertoire of mouse ultrasonic vocalizations (Fig. 1) includes syllables of highly variable durations (from $<10$ to $270 \mathrm{~ms}$ ), we analyzed the distribution of call durations to determine whether the reduced call duration in $m d x$ mice (Fig. 6c) was due to the use of distinct call subtypes. Indeed, the distribution of call durations selectively differed between genotypes during exposure to anesthetized females $(p<0.005$; Fig. $7 \mathrm{a})$ and $m d x$ intruder males $(p<0.005$; Fig. $7 \mathrm{~b})$, as $m d x$ residents produced more calls of a short duration and less calls of a long duration $(p<0.05)$. Hence, this qualitative change in the vocal repertoire in $m d x$ mice, confirmed by qualitative changes in call structure in the same experimental contexts (see Fig. $7 \mathrm{c}-\mathrm{f}$ ), suggests that $m d x$ and WT mice indeed used a distinct repertoire of syllables in response to specific social stimuli.

\section{Discussion}

This study provides the first evidence of abnormal social behavior and communication in the $m d x$ mouse model of DMD, which presents a nonsense point mutation leading to complete loss of the full-length dystrophin protein. This supports the hypothesis that dmd gene mutations may contribute to the emergence of autistic traits in this syndrome. It is noteworthy that stereotypic behaviors often observed in mouse models of autism, such as altered patterns of grooming activity or repetitive jumping [32], were not a feature of the $m d x$ mouse phenotype. However, stereotypies are not systematically detected in mouse models of ASD (e.g., [33]) and the entirety of the cardinal symptoms of ASD is not always expressed in autistic patients [7]. Repetitive behaviors have not been reported in DMD/BMD patients with ASD, suggesting that these syndromes are not associated with stereotypies. Here, we show that $m d x$ mice display context-specific behavioral and acoustic alterations, which are likely influenced by the degree of executive/ 
Table 2 Resident-intruder agonistic interactions. Behavioral parameters are grouped in three categories: Quality of contact, aggressive behaviors, and other behavioral responses. Only the significant statistical effects are shown ( $p$ values; ANOVAs with repeated measures) to highlight the effects of intruder's genetic background (within-subject factor: $\mathrm{C} 3 \mathrm{H}$ versus balb/c) and resident's genotype (between-subject factor: $m d x$ versus WT). The direction of the genotype differences is indicated in brackets

\begin{tabular}{|c|c|c|c|}
\hline Behavioral responses & Effect of intruder's genetic background & Effect of resident's genotype & Intruder $\times$ resident interaction \\
\hline \multicolumn{4}{|l|}{ Quality of contact } \\
\hline Orofacial $(n)$ & $p<0.001(\mathrm{C} 3 \mathrm{H}>$ balb $)$ & - & - \\
\hline Orofacial (duration, s) & $p<0.001(\mathrm{C} 3 \mathrm{H}>$ balb $)$ & - & - \\
\hline Orogenital (n) & - & - & - \\
\hline Orogenital (duration, s) & - & - & - \\
\hline Other $(n)$ & - & - & - \\
\hline Other (duration, s) & - & - & - \\
\hline \multicolumn{4}{|l|}{ Aggressive behaviors } \\
\hline Pursuits ( $n$ ) & $p<0.05(\mathrm{C} 3 \mathrm{H}>$ balb $)$ & - & - \\
\hline Pursuits (duration, s) & - & - & - \\
\hline Resident dominant acts $(n)$ & $p=0.01(\mathrm{C} 3 \mathrm{H}>$ balb $)$ & - & - \\
\hline Resident dominant acts (duration, s) & $p<0.001(\mathrm{C} 3 \mathrm{H}>$ balb $)$ & - & - \\
\hline Intruder dominant acts $(n)$ & - & - & $P<0.05$ \\
\hline Intruder dominant acts (duration, s) & - & - & $p=0.09, \mathrm{NS}$ \\
\hline \multicolumn{4}{|l|}{ Other behavioral responses } \\
\hline Rearings $(n)$ & - & $p<0.05(m d x<\mathrm{WT})$ & - \\
\hline Rearings (duration, s) & - & $P<0.05(m d x<$ WT $)$ & - \\
\hline Freezing during interaction $(n)$ & $p<0.001(\mathrm{C} 3 \mathrm{H}>$ balb $)$ & $P<0.05(m d x>W T)$ & - \\
\hline Freezing during interaction (duration, s) & $p<0.001(\mathrm{C} 3 \mathrm{H}>$ balb $)$ & $P<0.05(m d x>W T)$ & $P<0.05$ \\
\hline Freezing apart from interaction $(n)$ & $p<0.05(\mathrm{C} 3 \mathrm{H}>$ balb $)$ & - & - \\
\hline Freezing apart from interaction (duration, s) & - & - & - \\
\hline
\end{tabular}

cognitive demand and by emotional and conative factors.

\section{Context-specific alterations in social behavior}

The context-specific changes in social behavior in $m d x$ mice suggest specific defects in the behavioral functions involved in the processing of socially relevant information, which may include alterations in emotional reactivity, aggressiveness, and executive functioning. While in the three-chambered test, there were no deficits in sociability, social novelty preference, and short-term memory of social stimuli, during reciprocal interactions in a novel environment, $m d x$ mice exhibited altered social behavior. The main difference between these two paradigms is that in the former, intruders are spatially confined and thus behaviorally restricted, while in the latter, direct social encounters require organization of sequences of actions to adapt rapidly to the unpredicted behavior of the intruder mouse. In this situation, $m d x$ mice displayed reduced number of contacts with females or with $m d x$ male intruders, while the number of contacts with WT intruders was conversely increased, suggesting alterations in adaptive behaviors and thus in executive functions.

Interestingly, when $m d x$ mice were confronted with an intruder in their home cage they displayed an increased freezing response selectively during physical contacts, while they went back to normal exploratory activity upon interruption of social contact. This suggested that enhanced fear-related responses could also contribute to the altered social behavior in $m d x$ mice [34, 35]. This was associated with an increased number of dominant acts and pursuits initiated by control intruders towards $m d x$ residents, suggesting that enhanced emotional reactivity in $m d x$ mice might have influenced social hierarchy and/or aggressiveness during interactions with WT mice. However, fear-related responses were not observed in all experimental conditions. Moreover, $m d x$ social behavior also varied depending on intruders' trait behavior and genetic background (e.g., low versus highly aggressive genetic backgrounds). Such context-specific disturbances further support that executive functions enabling adaptation of behavior to distinct contexts and different types of intruders are affected in $m d x$ mice. 


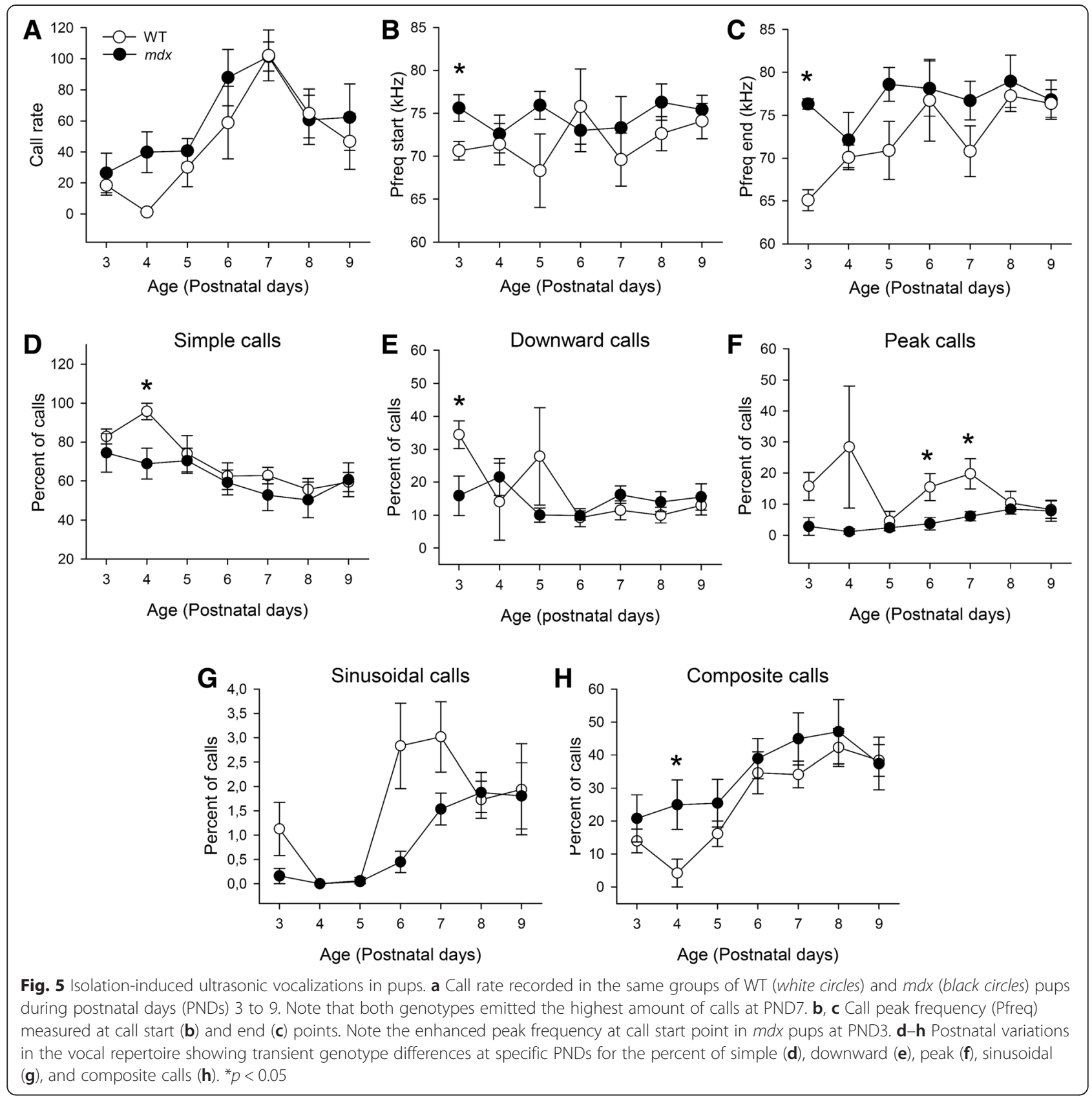

\section{Altered ultrasonic communication}

The study of ultrasonic communication in mice is a useful means to unveil phenotypic traits in mouse models of diverse speech and neurodevelopmental disorders including autism [27, 36-38]. Mouse USVs consist in different syllable types produced in bouts that follow a song-like structure, based on call-pattern mechanisms similar to those observed in primates, thus providing a mammalian model to study vocal learning and human disorders associated with speech or communication impairments [39]. Mice normally produce complex ultrasonic vocalizations in response to various sexual and social stimuli [25, 37], which is interpreted as a communicative behavior enabling mother mice to retrieve their pups after removal from the nest during the postnatal period and modulating mice social interactions in adulthood $[40,41]$. Here, we show that the production of isolation-induced USVs progressively increases from PND3 to PND9 in both $m d x$ and WT pups, as expected [24]. However, transient alterations were observed in $m d x$ pups at specific postnatal ages, as also demonstrated in other autism-relevant mouse models [24, 42]. First, there was an abnormal increase in call peak frequency in $m d x$ pups at PND3. According to playback 


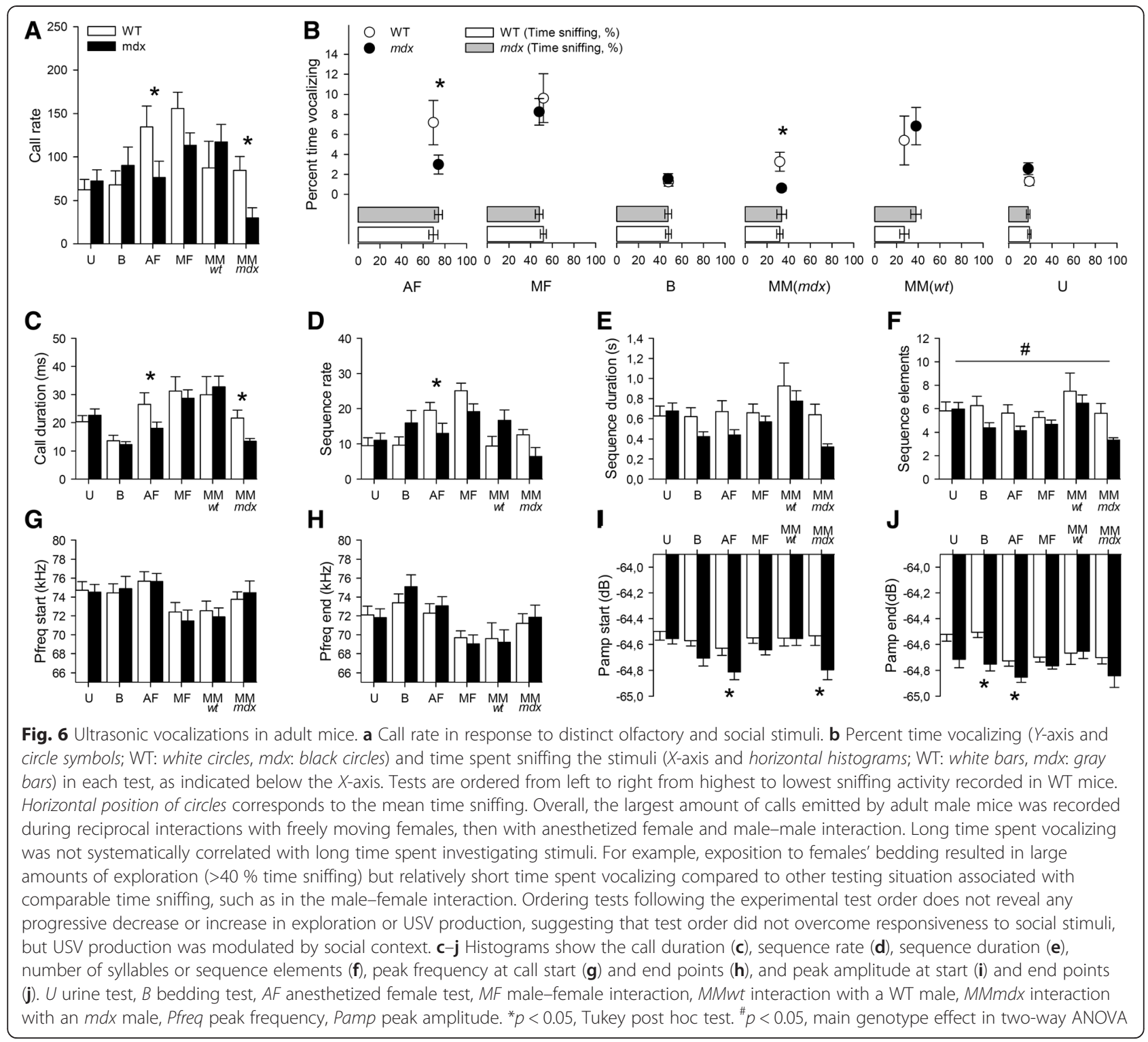

experiments [43], mother mice may show a stronger response towards a $65-45 \mathrm{kHz}$ signal than to a $75-55 \mathrm{kHz}$ signal, perhaps because high frequencies propagate less than low frequencies, suggesting that high peak frequencies decrease the functional value of pups "alarm" calls. The second alteration found in $m d x$ pups was a change in the frequency modulation patterns at PND3-4 and PND6-7. Postnatal development was associated with a progressive increase in the proportion of highly frequency-modulated calls, such as sinusoidal (i.e., complex) and composite (i.e., frequency jump) calls, and such frequency modulations are believed to be critical for maternal behavior [44]. However, $m d x$ pups emitted less "simple" downward calls at PND3 and peak calls at PND6-7, while they displayed more composite calls at PND4 compared to WT mice. This suggests that neonate $m d x$ mice use a more complex repertoire of calls compared to WT mice. Interestingly, such changes in mice vocalization repertoire have been previously associated with changes in emotional reactivity or arousal and are consistent with the profile of communication alterations in other rodent models of autism [24, 40].

Context-specific alterations in USVs were also found in adult $m d x$ mice and were characterized by a selective reduction in the quantity of vocalizations emitted in presence of anesthetized females and during interactions with other $m d x$ male mice. A more modest and nonsignificant reduction in call rate was also observed during interaction with freely moving females. In contrast, the USVs emitted in low-noise situations in response to potent volatile sexual olfactory stimuli (proestrous-estrous female urine on a cotton swab) or to a 


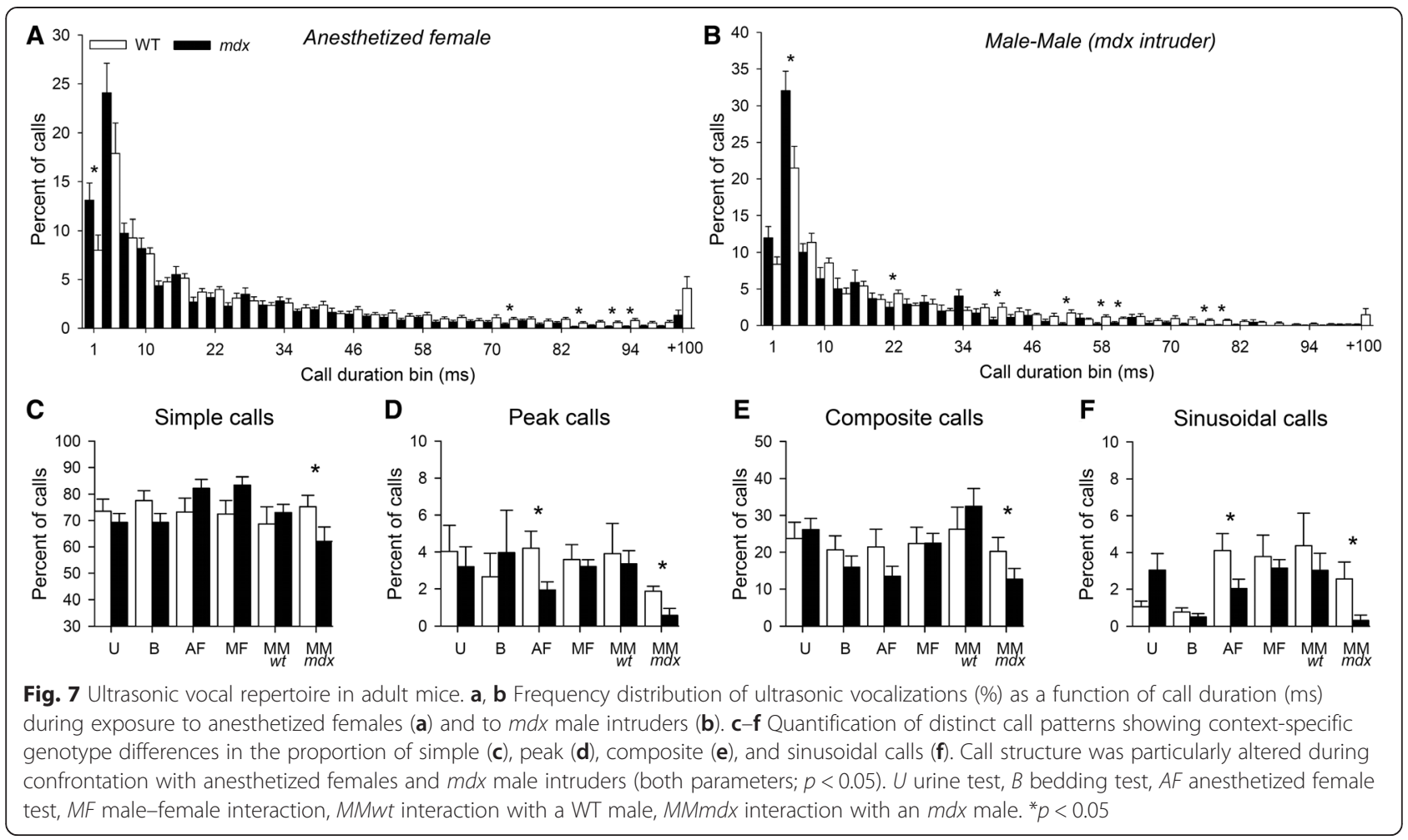

combination of volatile and non-volatile sexual stimuli (exploration of female cage bedding) did not reveal major changes in call rate and duration, suggesting that main and accessory olfactory systems are unaltered in $m d x$ mice $[45,46]$. Also, a putative influence of motor or muscular defects is unlikely. Indeed, the intrinsic laryngeal muscles involved in vocal production by controlling the position and tension of the vocal folds are spared from the dystrophic process in the $m d x$ mouse [47]. Although a deficient motor coordination in $m d x$ mice [48] could alter the genesis of USVs, as suggested by studies in the Foxp2-deficient mouse [36, 49], this could not explain the selectivity of the deficits in $m d x$ mice. Moreover, the recordings performed in presence of an anesthetized female enabled USV analysis in low background noise and ruled out possible biases due to the putative production of USVs by intruders. Our data therefore show that USVs are specifically affected in $m d x$ mice in social contexts and more likely depended on altered social motivation.

The USVs normally emitted in the presence of females are thought to facilitate approach behavior and copulation [50], while during male-male encounters they have been associated with expression of affiliative behaviors [25]. When $m d x$ mice were submitted to dyadic interactions with either WT females or $m d x$ male intruders in a novel environment, the reduced number of vocalizations was associated with a reduced number of contacts initiated by $m d x$ residents. Conversely, a slight increase in call rate was associated with an increased number of contacts initiated by $m d x$ residents towards WT male intruders. In these situations $m d x$ calls had shorter durations and amplitudes, two parameters remarked as prosodic elements conveying critical emotional or motivational information for social interactions [51]. Accordingly, call duration has been shown to be modulated by social motivation [25] and reduced in mouse models of autism [27]. Here, we also demonstrate that adult $m d x$ mice used an abnormal vocal repertoire in specific social contexts, i.e., a reduced expression of peak and composite calls in presence of anesthetized females and of sinusoidal and simple calls in male-male encounters. The composition of an adult mouse repertoire normally depends on the context and previous social experience [25]. Short and composite calls are considered as "basic" calls found in many behavioral context whereas upward, frequency jump, u-shape, flat, and chevron (i.e., peak) calls are predominantly found in social situations and therefore considered as more "informative" of the behavioral, emotional, or motivational content of these specific situations. Here, the altered vocal repertoire during male-male encounters was associated with a reduction in the number of contacts, suggesting a functional link between social behavior deficits and altered USVs in $m d x$ mice. The selectivity of the observed deficits likely depended on a change in social motivation. This might reflect an altered neural control of call production, perhaps due to the lack of Dp427 in neocortical principal 
neurons [52], in particular in the anterior cingulate cortex, which takes part in the volitional circuits associated with call onset [38]. Interestingly, some models of autism such as neuroligin-deficient mice have been shown to exhibit deficits in the production of complex calls during social interactions [53], while they were able to produce these calls in other contexts, which also suggests that the altered use of the vocal repertoire may reflect a deficit in behavioral responsiveness to social stimuli eliciting USVs [38].

\section{Relevance to DMD and ASD}

We show for the first time the presence of contextspecific disturbances in social behavior and ultrasonic communication in the dystrophin-deficient $m d x$ mouse. Hence, mutations selectively affecting the expression of the full-length Dp427, a common genetic alteration in all DMD patients, appear to be sufficient to significantly alter social behavior and communication. This is in agreement with a case study reporting ASD in a DMD patient holding a mutation that selectively impairs Dp427 expression [15]. Mutations that affect expression of the other C-terminal brain forms of dystrophin have been associated with mental retardation. Therefore, the general observation of social behavior deficits in DMD patients that do not display mental retardation also supports a role for Dp427 in social behavior [10]. Nevertheless, patients with intellectual quotients in the normal range may exhibit deficits in executive functions [3], which might contribute to the emergence of both social behavior and communication deficits.

In $m d x$ pups, transient alterations in USVs are readily detectable during the first postnatal week, while social behavior deficits in the adults are associated with the use of an abnormal vocal repertoire of vocalizations in specific social contexts, suggesting alterations in the executive control of social motivation, adaptive behavior and communication. Strikingly, delayed speech development, limited expressive and receptive vocabulary, reduced verbal fluency, and verbal short-term working memory have been described in DMD patients $[54,55]$ and associated with alterations in adaptive and social skills $[10,12]$. Even when ASD is not diagnosed, DMD patients may display moderate weaknesses in social behavior and communication, including language difficulties, tendency of being withdrawn, avoidance of eye contact, difficulties in interpreting facial affect, and problems with theory of mind [56]. Social behavior relies on the functional integrity of the prefrontal cortex and cerebellum $[57,58]$. Dysfunctional cortical-cerebellar circuits have been associated with autism [59], and this has also been proposed as a neural basis of the defective social and executive functions in DMD patients [2]. While impairments in executive functions have not been clearly characterized in the $m d x$ mouse, this model displays memory deficits, altered synaptic plasticity and enhanced fearfulness [34, 60], suggesting that both cognitive and conative disturbances due to Dp427 loss could contribute to the social behavior and USV alterations.

The mechanisms responsible for emergence of autistic symptoms in DMD patients are still unclear, although one likely hypothesis is an alteration of the molecular interactions between the dystrophin complex and the trans-synaptic neurexin-neuroligin complex in central inhibitory synapses [18]. Dystrophin is selectively involved in the organization of central inhibitory postsynaptic scaffolds by contributing to the recruitment of neuroligin-2 (NLGN2) $[19,61,62]$, a synaptic cell adhesion protein involved in structural remodeling of connectivity networks which has been proposed as a candidate gene for ASD [63]. Synaptic molecular alterations specifically due to Dp427 loss in $m d x$ mice are characterized by a delocalization of NLGN2 and presynaptic vesicular GABA transporter (VGAT) and a reduction of NLGN2 colocalization with alpha-1 subunit-containing $\mathrm{GABA}_{\mathrm{A}}$ receptors within hippocampal synaptic layers, suggesting a modification of the molecular mechanisms that normally underlie precise spatio-temporal pattern of GABAergic transmission [61]. Dystrophin loss also alters synapse ultrastructure, clustering of distinct subtypes of $\mathrm{GABA}_{\mathrm{A}}$ receptors, central inhibitory function, and synaptic plasticity, which has been associated with disturbances in fear-related behaviors, anxiety, and cognitive functions [34, 64-66]. Interestingly, rodent models overexpressing NLGN2 display deficits in reciprocal social interactions and stereotypies $[67,68]$, while in the knockout model, a reduced production of isolation-induced calls has been reported in pups [69], but no overt impairment in social behavior was found in the adult. Future pharmacological approaches aimed at compensating altered GABAergic function or restoring dystrophin function in $m d x$ mice might be helpful to further delineate the physiopathology of autistic traits in DMD, to highlight the importance of the neuroligin and neurexin complex in ASD and to unveil new leads to alleviate behavioral symptoms in DMD patients.

\section{Conclusions}

Our study provides the first evidence that mutations impeding expression of the brain full-length dystrophin affect social behavior and communication. The deficits displayed by $m d x$ mice support the hypothesis that altered social cognition may confer vulnerability to autism in DMD. The context-specific changes in social behavior and communication in $m d x$ mice likely depend on the different behavioral/emotional demands associated with specific test conditions. How such alterations may 
contribute to the occurrence of ASD in restricted subpopulation of DMD patients remains to be determined. In ASD, only rare cases can be ascribed to single-gene defects, while multiple interacting genetic factors appear to be the main causative determinants of "idiopathic" autism, and epigenetic/environmental factors may also contribute to the variable expression of autism-related traits [70-72]. This multi-hit hypothesis likely applies to the DMD condition, in which a full autistic-like phenotype would only be achieved in some patients when the mutation in the $d m d$ gene alters expression of additional C-terminal dystrophin products [73] and/or when additional mutations or copy number variations (CNVs) in other genes disturb expression of other synaptic proteins, leading to cumulative deficits that would then meet criteria for ASD diagnosis [14, 74, 75]. Therefore, correlations between the patient's genotype and presence of autism should be systematically analyzed in DMD patients and could include searches for additional genomic abnormalities beyond dmd gene mutations. Conversely, specific mutations in the dmd gene lead to late onset and mild muscular phenotypes, as illustrated in patients cases with such mutations that only displayed mental retardation or autistic-like behaviors [14, 76], and some of these genetic alterations likely have been missed or underestimated in former genome-wide studies of patients with idiopathic autism [75, 77]. Therefore, higher resolution mutation screening of the $D M D$ gene in ASD patients should be encouraged.

\section{Additional files}

Additional file 1: Supplementary method section. Semi-automatic classification of mouse USVs. (PDF $144 \mathrm{~kb}$ )

Additional file 2: Figure S1. Exploration of female olfactory stimuli. (DOC $317 \mathrm{~kb}$ )

Additional file 3: Supplementary result section. Correlation analyses. (PDF $37 \mathrm{~kb}$ )

\begin{abstract}
Abbreviations
ANOVA: analysis of variance; ASD: autism spectrum disorders; BMD: Becker muscular dystrophy; CNVs: copy number variations; DMD: Duchenne muscular dystrophy; Dp427: 427-kDa cytoskeleton-associated dystrophin protein; FFT: fast Fourier transform; GABA: gamma-aminobutyric acid; IP: intraperitoneal; KS: Kolmogorov-Smirnov; NLGN1-4: neuroligin family of synaptic cell adhesion proteins; Pamp: call peak amplitude; Pfreq: call peak frequency; PND: postnatal day; USV: ultrasonic vocalization; VBA: visual basic for applications; VGAT: presynaptic vesicular GABA transporter; WT: wild type.
\end{abstract}

\section{Competing interests}

The authors declare that they have no competing interests.

\section{Authors' contributions}

RM and CV designed the study, acquired data, and wrote and reviewed the manuscript, TA designed the study and reviewed the manuscript, FN and $\mathrm{BB}$ contributed to the analysis and interpretation of the data and reviewed the manuscript, and SL participated in the interpretation of data and reviewed the manuscript. All authors approved the final version of the manuscript.

\section{Acknowledgements}

This work was supported by the AFM (Association Française contre les Myopathies, France, (NeuroDYS project, grant \#15299 to C.V.), the Agence Nationale de la Recherche (DYSther project, Grant ANR-14-CE13 0037-01 to C.V.), the Spanish Ministry of Science and Innovation ("José Castillejo" grant \#JC2008-00249 to R.M.), the Centre National de la Recherche Scientifique (France), and the University Paris-Sud (France). The authors are grateful to V. Halin-Marsaux for building the threechambered box and to P. Leblanc-Veyrac and N. Samson for mouse breeding, care, and genotyping.

\section{Author details}

'CNRS, Neuroscience Paris Saclay Institute, UMR 9197, Orsay 91405, France. ${ }^{2}$ Univ Paris-Sud, UMR 9197, Orsay 91405, France. ${ }^{3}$ Present address: Department of Psychobiology, Universidad Complutense de Madrid, Ciudad Universitaria, 28040 Madrid, Spain.

Received: 13 February 2015 Accepted: 22 October 2015

Published online: 29 October 2015

\section{References}

1. Persico AM, Bourgeron T. Searching for ways out of the autism maze: genetic, epigenetic and environmental clues. Trends Neurosci. 2006;29:349-58.

2. Cyrulnik SE, Hinton VJ. Duchenne muscular dystrophy: a cerebellar disorder? Neurosci Biobehav Rev. 2008;32:486-96.

3. Snow WM, Anderson JE, Jakobson LS. Neuropsychological and neurobehavioral functioning in Duchenne muscular dystrophy: a review. Neurosci Biobehav Rev. 2013;37:743-52.

4. Wu JY, Kuban KC, Allred E, Shapiro F, Darras BT. Association of Duchenne muscular dystrophy with autism spectrum disorder. J Child Neurol. 2005;20:790-5

5. Hendriksen JG, Vles JS. Neuropsychiatric disorders in males with Duchenne muscular dystrophy: frequency rate of attention-deficit hyperactivity disorder (ADHD), autism spectrum disorder, and obsessive-compulsive disorder. J Child Neurol. 2008;23:477-81.

6. Hinton VJ, Cyrulnik SE, Fee RJ, Batchelder A, Kiefel JM, Goldstein EM, et al. Association of autistic spectrum disorders with dystrophinopathies. Pediatr Neurol. 2009;41:339-46.

7. American Psychiatric Association. Diagnostic and statistical manual of mental disorders. 5th ed. Arlington (VA): American Psychiatric Publishing; 2013.

8. Donders J, Taneja C. Neurobehavioral characteristics of children with Duchenne muscular dystrophy. Child Neuropsychol. 2009:15:295-304.

9. Verhoeven JS, De Cock P, Lagae L, Sunaert S. Neuroimaging of autism Neuroradiology. 2010;52:3-14.

10. Hinton VJ, Nereo NE, Fee RJ, Cyrulnik SE. Social behavior problems in boys with Duchenne muscular dystrophy. J Dev Behav Pediatr. 2006:27:470-6.

11. Hinton VJ, Fee RJ, De Vivo DC, Goldstein E. Poor facial affect recognition among boys with Duchenne muscular dystrophy. J Autism Dev Disord. 2007:37:1925-33.

12. Cyrulnik SE, Fee RJ, Batchelder A, Kiefel J, Goldstein E, Hinton VJ. Cognitive and adaptive deficits in young children with Duchenne muscular dystrophy (DMD). J Int Neuropsychol Soc. 2008;14:853-61.

13. Taylor PJ, Betts GA, Maroulis S, Gilissen C, Pedersen RL, Mowat DR, et al. Dystrophin gene mutation location and the risk of cognitive impairment in Duchenne muscular dystrophy. PLoS One. 2010;5:e8803.

14. Pagnamenta AT, Holt R, Yusuf M, Pinto D, Wing K, Betancur C, et al. A family with autism and rare copy number variants disrupting the Duchenne/ Becker muscular dystrophy gene DMD and TRPM3. J Neurodev Disord. 2011:3:124-31

15. Erturk O, Bilguvar K, Korkmaz B, Bayri Y, Bayrakli F, Arlier Z, et al. A patient with Duchenne muscular dystrophy and autism demonstrates a hemizygous deletion affecting dystrophin. Am J Med Genet A. 2010;152A:1039-42.

16. Waite A, Brown SC, Blake DJ. The dystrophin-glycoprotein complex in brain development and disease. Trends Neurosci. 2012;35:487-96.

17. Zikopoulos B, Barbas H. Altered neural connectivity in excitatory and inhibitory cortical circuits in autism. Front Hum Neurosci. 2013;7:609.

18. Craig AM, Kang Y. Neurexin-neuroligin signaling in synapse development. Curr Opin Neurobiol. 2007;17:43-52 
19. Patrizi A, Scelfo B, Viltono L, Briatore F, Fukaya $M$, Watanabe $M$, et al. Synapse formation and clustering of neuroligin-2 in the absence of GABAA receptors. Proc Natl Acad Sci U S A. 2008;105:13151-6.

20. Südhof TC. Neuroligins and neurexins link synaptic function to cognitive disease. Nature. 2008;455:903-11.

21. Sicinski P, Geng Y, Ryder-Cook AS, Barnard EA, Darlison MG, Barnard PJ. The molecular basis of muscular dystrophy in the mdx mouse: a point mutation. Science. 1989:244:1578-80.

22. Perronnet C, Chagneau C, Le Blanc P, Samson-Desvignes N, Mornet D, Laroche $\mathrm{S}$, et al. Upregulation of brain utrophin does not rescue behavioral alterations in dystrophin-deficient mice. Hum Mol Genet. 2012;21:2263-76.

23. Holy TE, Guo Z. Ultrasonic songs of male mice. PLoS Biol. 2005;3:e386.

24. Scattoni ML, Gandhy SU, Ricceri L, Crawley JN. Unusual repertoire of vocalizations in the BTBR T+tf/J mouse model of autism. PLoS One. 2008;3:e3067.

25. Chabout J, Serreau P, Ey E, Bellier L, Aubin T, Bourgeron T, et al. Adult male mice emit context-specific ultrasonic vocalizations that are modulated by prior isolation or group rearing environment. PLoS One. 2012;7:e29401.

26. Fujita E, Tanabe Y, Imhof BA, Momoi MY, Momoi T. Cadm1-expressing synapses on Purkinje cell dendrites are involved in mouse ultrasonic vocalization activity. PLoS One. 2012;7:e30151.

27. Ey E, Torquet N, Le Sourd AM, Leblond CS, Boeckers TM, Faure P, et al. The autism ProSAP1/Shank2 mouse model displays quantitative and structural abnormalities in ultrasonic vocalisations. Behav Brain Res. 2013;256:677-89.

28. Hoffmann F, Musolf K, Penn DJ. Freezing urine reduces its efficacy for eliciting ultrasonic vocalizations from male mice. Physiol Behav. 2009;96:602-5.

29. Nadler JJ, Moy SS, Dold G, Trang D, Simmons N, Perez A, et al. Automated apparatus for quantitation of social approach behaviors in mice. Genes Brain Behav. 2004;3:303-14

30. Saudou F, Amara DA, Dierich A, LeMeur M, Ramboz S, Segu L, et al. Enhanced aggressive behavior in mice lacking $5-\mathrm{HT} 1 \mathrm{~B}$ receptor. Science. 1994:265:1875-8

31. Southwick $\mathrm{CH}$, Clark LH. Aggressive behaviour and exploratory activity in fourteen mouse strains. Am Zool. 1966;6:559.

32. Silverman JL, Yang M, Lord C, Crawley JN. Behavioural phenotyping assays for mouse models of autism. Nat Rev Neurosci. 2010;11:490-502.

33. Jamain S, Radyushkin K, Hammerschmidt K, Granon S, Boretius S, Varoqueaux $F$, et al. Reduced social interaction and ultrasonic communication in a mouse model of monogenic heritable autism. Proc Natl Acad Sci U S A. 2008;105:1710-5.

34. Sekiguchi M, Zushida K, Yoshida M, Maekawa M, Kamichi S, Yoshida M, et al. A deficit of brain dystrophin impairs specific amygdala GABAergic transmission and enhances defensive behaviour in mice. Brain. 2009;132:124-35.

35. Yamamoto K, Yamada D, Kabuta T, Takahashi A, Wada K, Sekiguchi M. Reduction of abnormal behavioral response to brief restraint by information from other mice in dystrophin-deficient mdx mice. Neuromuscul Disord. 2010;20:505-11.

36. Fujita E, Tanabe $Y$, Shiota A, Ueda M, Suwa K, Momoi MY, et al. Ultrasonic vocalization impairment of Foxp2 (R552H) knockin mice related to speechlanguage disorder and abnormality of Purkinje cells. Proc Natl Acad Sci U S A. 2008;105:3117-22

37. Scattoni ML, Crawley J, Ricceri L. Ultrasonic vocalizations: a tool for behavioural phenotyping of mouse models of neurodevelopmental disorders. Neurosci Biobehav Rev. 2009:33:508-15.

38. Fischer J, Hammerschmidt K. Ultrasonic vocalizations in mouse models for speech and socio-cognitive disorders: insights into the evolution of vocal communication. Genes Brain Behav. 2011;10:17-27.

39. Hage SR, Gavrilov N, Salomon F, Stein AM. Temporal vocal features suggest different call-pattern generating mechanisms in mice and bats. BMC Neurosci. 2013;14:99

40. Ehret G. Infant rodent ultrasounds - a gate to the understanding of sound communication. Behav Genet. 2005;35:19-29.

41. Portfors CV. Types and functions of ultrasonic vocalizations in laboratory rats and mice. J Am Assoc Lab Anim Sci. 2007;46:28-34.

42. Jiang $Y H$, Pan $Y$, Zhu L, Landa L, Yoo J, Spencer $C$, et al. Altered ultrasonic vocalization and impaired learning and memory in Angelman syndrome mouse model with a large maternal deletion from Ube3a to Gabrb3. PLoS One. 2010;5:e12278.
43. Smith JC. Responses to adult mice to models infant calls. J Comp Physiol Psychol. 1976;90:1105-15.

44. Wöhr M, Roullet Fl, Hung AY, Sheng M, Crawley JN. Communication impairments in mice lacking Shank1: reduced levels of ultrasonic vocalizations and scent marking behavior. PLoS One. 2011;6:e20631.

45. Grimsley JM, Monaghan JJ, Wenstrup JJ. Development of social vocalizations in mice. PLoS One. 2011;6:e17460.

46. Pankevich DE, Baum MJ, Cherry JA. Olfactory sex discrimination persists, whereas the preference for urinary odorants from estrous females disappears in male mice after vomeronasal organ removal. J Neurosci. 2004;24:9451-7.

47. Thomas LB, Joseph GL, Adkins TD, Andrade FH, Stemple JC. Laryngeal muscles are spared in the dystrophin deficient mdx mouse. J Speech Lang Hear Res. 2008:51:586-95.

48. Grady RM, Wozniak DF, Ohlemiller KK, Sanes JR. Cerebellar synaptic defects and abnormal motor behavior in mice lacking alpha- and beta-dystrobrevin. J Neurosci. 2006:26:2841-51.

49. Shu W, Cho JY, Jiang Y, Zhang M, Weisz D, Elder GA, et al. Altered ultrasonic vocalization in mice with a disruption in the Foxp2 gene. Proc Natl Acad Sci U S A. 2005;102:9643-8.

50. Hammerschmidt K, Radyushkin K, Ehrenreich H, Fischer J. Female mice respond to male ultrasonic 'songs' with approach behaviour. Biol Lett. 2009:5:589-92

51. Lahvis GP, Alleva E, Scattoni ML. Translating mouse vocalizations: prosody and frequency modulation. Genes Brain Behav. 2011;10:4-16.

52. Lidov HG, Byers TJ, Kunkel LM. The distribution of dystrophin in the murine central nervous system: an immunocytochemical study. Neuroscience. 1993;54:167-87.

53. Kleijer KT, Schmeisser MJ, Krueger DD, Boeckers TM, Scheiffele P, Bourgeron T, et al. Neurobiology of autism gene products: towards pathogenesis and drug targets. Psychopharmacology (Berl). 2014;231:1037-62.

54. Cotton S, Voudouris NJ, Greenwood KM. Intelligence and Duchenne muscular dystrophy: full-scale, verbal, and performance intelligence quotients. Dev Med Child Neurol. 2001;43:497-501.

55. Cotton SM, Voudouris NJ, Greenwood KM. Association between intellectual functioning and age in children and young adults with Duchenne muscular dystrophy: further results from a meta-analysis. Dev Med Child Neurol. 2005; $47: 257-65$

56. Poysky J. Behavior patterns in Duchenne muscular dystrophy: report on the parent project muscular dystrophy behavior workshop 8-9 of December 2006, Philadelphia, USA. Neuromusc Disord. 2007;17:986-94.

57. Coura RS, Cressant A, Xia J, de Chaumont F, Olivo-Marin JC, Pelloux Y, et al. Nonaggressive and adapted social cognition is controlled by the interplay between noradrenergic and nicotinic receptor mechanisms in the prefrontal cortex. FASEB J. 2013;27:4343-54.

58. Riva D, Cazzaniga F, Esposito S, Bulgheroni S. Executive functions and cerebellar development in children. Appl Neuropsychol Child. 2013;2:97-103

59. Frith U. Mind blindness and the brain in autism. Neuron. 2001;32:969-79.

60. Perronnet C, Vaillend C. Dystrophins, utrophins, and associated scaffolding complexes: role in mammalian brain and implications for therapeutic strategies. J Biomed Biotechnol. 2010;2010:849426.

61. Krasowska E, Zabłocki K, Górecki DC, Swinny JD. Aberrant location of inhibitory synaptic marker proteins in the hippocampus of dystrophindeficient mice: implications for cognitive impairment in Duchenne muscular dystrophy. PLoS One. 2014;9:e108364.

62. Sumita K, Sato Y, lida J, Kawata A, Hamano M, Hirabayashi S, et al. Synaptic scaffolding molecule (S-SCAM) membrane-associated guanylate kinase with inverted organization (MAGI)-2 is associated with cell adhesion molecules at inhibitory synapses in rat hippocampal neurons. J Neurochem. 2007;100:154-66

63. Belligni EF, Di Gregorio E, Biamino E, Calcia A, Molinatto C, Talarico F, et al. $790 \mathrm{~Kb}$ microduplication in chromosome band 17p13.1 associated with intellectual disability, afebrile seizures, dysmorphic features, diabetes, and hypothyroidism. Eur J Med Genet. 2012;55:222-4.

64. Knuesel I, Mastrocola M, Zuellig RA, Bornhauser B, Schaub MC, Fritschy JM. Short communication: altered synaptic clustering of GABAA receptors in mice lacking dystrophin (mdx mice). Eur J Neurosci. 1999;11:4457-62.

65. Vaillend C, Billard JM, Laroche S. Impaired long-term spatial and recognition memory and enhanced CA1 hippocampal LTP in the dystrophin-deficient Dmd (mdx) mouse. Neurobiol Dis. 2004;17:10-20. 
66. Miranda R, Sébrié C, Degrouard J, Gillet B, Jaillard D, Laroche S, et al. Reorganization of inhibitory synapses and increased PSD length of perforated excitatory synapses in hippocampal area CA1 of dystrophindeficient mdx mice. Cereb Cortex. 2009;19:876-88.

67. Hines RM, Wu L, Hines DJ, Steenland H, Mansour S, Dahlhaus R, et al. Synaptic imbalance, stereotypies, and impaired social interactions in mice with altered neuroligin 2 expression. J Neurosci. 2008;28:6055-67.

68. Kohl C, Riccio O, Grosse J, Zanoletti O, Fournier C, Schmidt MV, et al. Hippocampal neuroligin-2 overexpression leads to reduced aggression and inhibited novelty reactivity in rats. PLoS One. 2013;8:e56871.

69. Wöhr M, Silverman JL, Scattoni ML, Turner SM, Harris MJ, Saxena R, et al. Developmental delays and reduced pup ultrasonic vocalizations but normal sociability in mice lacking the postsynaptic cell adhesion protein neuroligin2. Behav Brain Res. 2013;251:50-64

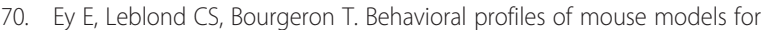
autism spectrum disorders. Autism Res. 2011;4:5-16.

71. Belmonte MK, Bourgeron T. Fragile $X$ syndrome and autism at the intersection of genetic and neural networks. Nat Neurosci. 2006;9:1221-5.

72. Pinto D, Pagnamenta AT, Klei L, Anney R, Merico D, Regan $R$, et al. Functional impact of global rare copy number variation in autism spectrum disorders. Nature. 2010;466:368-72.

73. Qiao Y, Tyson C, Hrynchak M, Lopez-Rangel E, Hildebrand J, Martell S, et al. Clinical application of 2.7 M Cytogenetics array for CNV detection in subjects with idiopathic autism and/or intellectual disability. Clin Genet. 2013;83:145-54.

74. Yamakawa H, Oyama S, Mitsuhashi H, Sasagawa N, Uchino S, Kohsaka S, et al. Neuroligins 3 and $4 \times$ interact with syntrophin-gamma2, and the interactions are affected by autism-related mutations. Biochem Biophys Res Commun. 2007;355:41-6

75. Gai X, Xie HM, Perin JC, Takahashi N, Murphy K, Wenocur AS, et al. Rare structural variation of synapse and neurotransmission genes in autism. Mol Psychiatry. 2012;17:402-11.

76. de Brouwer AP, Nabuurs SB, Verhaart IE, Oudakker AR, Hordijk R, Yntema HG, et al. A 3-base pair deletion, c.9711_9713del, in DMD results in intellectual disability without muscular dystrophy. Eur J Hum Genet. 2014;22:480-5.

77. Chung RH, Ma D, Wang K, Hedges DJ, Jaworski JM, Gilbert JR, et al. An X chromosome-wide association study in autism families identifies TBL1X as a novel autism spectrum disorder candidate gene in males. Mol Autism. $2011 ; 2: 18$

\section{Submit your next manuscript to BioMed Central and take full advantage of:}

- Convenient online submission

- Thorough peer review

- No space constraints or color figure charges

- Immediate publication on acceptance

- Inclusion in PubMed, CAS, Scopus and Google Scholar

- Research which is freely available for redistribution 